\title{
Students' Attitudes, Perceptions, and Engagement within a Flipped classroom model as Related to Learning Mathematics
}

\author{
Cary Moore \\ College of Education, California State University, Sacramento \\ 6000 J Street, Sacramento, California 95825, Untied States \\ Tel: 1-916-786-8676 E-mail: cmoore@rjuhsd.us \\ Chia-Jung Chung (Corresponding author) \\ College of Education, California State University, Sacramento \\ 6000 J Street, Sacramento, California 95825, Untied States \\ Tel: 1-916-278-6079 E-mail: cchung@csus.edu
}

Received: August 8, 2015 Accepted: August 28, 2015 Published: August 28, 2015

doi:10.5296/jse.v5i3.8131ＵRL:http://dx.doi.org/10.5296/jse.v5i3.8131

\begin{abstract}
The flipped classroom is an instructional method that can provide additional face-to-face interaction time with students in the classroom by minimizing the amount of direct instruction used in a traditional classroom setting. In this study, students in a high school Algebra 2 class who experienced a flipped classroom environment were surveyed to examine their attitudes, perceptions, and engagement of the flipped classroom and the elements that contribute to learning mathematics. The survey also addressed how the flipped classroom could be a motivating factor in learning mathematics. The survey used both quantitative and qualitative research measures to provide a broader understanding of how students perceive the attributes of flipping the classroom. In addition, student interviews helped gain insight into participants' feelings, attitudes, motivation, and engagement about mathematics due to the flipped classroom. Researcher observations and notes provided information as to student engagement within the classroom as a byproduct of using the inverted classroom instructional strategy. The results revealed that the perceptions and attitudes of the participants were
\end{abstract}




\section{Macrothink}

Journal of Studies in Education

ISSN 2162-6952

2015, Vol. 5, No. 3

generally positive in the flipped classroom environment. The students were motivated to use the web-based instructional videos to prepare for their expected learning outcomes.

Keywords: Flipped-Classroom, instructional video, perceptions, attitudes, engagement, motivation, participation 


\section{Introduction}

The purpose of this action research was to investigate whether the use of web-based instructional videos via a flipped classroom model in a high school mathematics class would affect the attitude, perceptions, or engagement of students. The study also examined whether the use of web-based videos would help increase student motivation to learn mathematics. The children of this generation are clearly more technologically literate than students were in the past. The use of technology in the classroom may be a motivator to increase learning of students and engagement with the content presented within a high school level curriculum, particularly mathematics. As technology continues to grow and change, teachers' and students' use of educational technology tools must also grow and change. One technological tool is the Flipped classroom model in which web-based instructional videos are used as a vehicle to instruct, remediate, or intervene for students on their own computers or mobile technology devices, such as Smartphones or iPads, from locations outside of the classroom. The flipped classroom gives students the opportunity to watch skills-focused, direct instruction, use web-based videos as homework and subsequently use the classroom time to practice the content of the lesson through various differentiated critical thinking activities.

\subsection{Significance of Study}

As the world continues to grow and adapt to the integration of technology into everyday life, so too has the way students are taught and how technology is used in today's classrooms. One of the goals of education (Common Core) is to encourage students to use critical thinking skills to solve curricular-based differentiated level problems. Using the flipped classroom model provides the platform from which students can take charge of their learning and gives both students and teachers the ability to develop higher-level critical thinking skills in a problem-posing student-centered learning environment. However, using web-based instruction does not guarantee students will even watch the direct instruction videos, let alone comprehend them. Therefore, several questions arise: How is technology outside the classroom being used to get students to achieve higher learning? How does technology help students gain greater access to course material - especially direct instructional videos? What type of educational technology helps students use their critical thinking skills? Does the use of educational technology outside of the classroom increase student engagement within the classroom? Will students consider using web-based instructional videos as a means to intervene for topics that are difficult to understand? The hope is that this research will identify that the flipped classroom provides students with increased productive attitudes, positive perceptions, and greater engagement in the area of mathematics.

\section{Review of Literature}

The use of technology in teaching and learning mathematics has become more prevalent with the availability of mathematics software and instructor/learner educational software to support mathematics curriculums. Over the last decade, a great reemphasis has been given to integrating educational technology into the mathematics classroom in order to help motivate students in the process of learning mathematical concepts to be used in real life problem solving activities. Technology is providing a new perspective to learning mathematics. 
With the advancement of educational technology, teaching methods and strategies have begun to evolve. Alternative models of teaching with technology have surfaced to better maintain the interest of today's digital generation in the classroom. Some of the prominent teaching models are the flipped classroom, Blended Learning, and Converted Classroom. Classrooms are becoming more learner-centered where time in the class is used for guided discussions, problem-solving tasks, and differentiated interactive content relevant activities. Yapici (2012) suggests Blended Learning, which combines the advantages of web-based learning with face-to-face hands-on activity rich learning, can lead to a successful learner-centered environment. Pioneered by two Colorado High School science teachers Bergmann and Sams, the flipped classroom approach to teaching has become more attractive because of the availability of web-based resources including audio and video instructional materials from authorities in core subjects, such as mathematics. In a flipped classroom, students are expected to view web-based resources before coming to class. Class-time, which traditionally is spent on direct-instruction, allows for more time to engage in discussions and learning activities. Millennial Generation students have access to these instructional videos produced by teachers, experts in their field of study, or sites such as the Khan Academy to view at their own pace and leisure. Herreid and Schiller (2013) reflect that flipping the classroom has the ability to engage students and develop critical-thinking skills, among other benefits. Strayer (2012) found that, in general, students in a Flipped Class were more willing to work together and engage in activities in the classroom than the students in a traditional classroom setting. Students in the flipped classroom were more willing to collaborate with other students. These students preferred more innovation in the flipped classroom when compared to those students in a traditional classroom. The current research supports the idea that the integration of technology into the classroom may be a motivating factor to learning course content by providing more interest for students in core subject classes. However, the same may not be said for improved academic outcomes. More research is needed to answer the question, "does the use of educational technology increase student knowledge?"

\subsection{Flipped-Classroom Model}

The flipped classroom may provide the means to develop an educational environment that promotes discovery learning, problem-based learning, experiential learning, and student-centered learning. The flipped classroom is an instructional model developed and popularized by Colorado science teachers Jonathan Bergmann and Aaron Sams (Bergmann \& Sams, 2012).In the flipped classroom, students learn new content by watching web-based instructional video lectures outside of the classroom (at home, at a friend's house, at the library, on mobile devices), and then develop depth of knowledge by applying those mathematical concepts to relevant hands-on activities in the classroom. As such, class time is used for discussion, collaborative problem solving, and differentiated learning activities. Strayer (2007) would suggest this environment could provide a framework for learning through activity. Students would develop an understanding of concepts by doing something rather than merely talking, listening, or thinking about them.

The flipped classroom instruction can be defined by a "teacher's willingness to help students learn how and when they see fit, release control of the classroom, and find the best way to 
reach and respond to students individually" (Bergmann\& Waddell, 2012, p.6).The attraction of the flipped classroom is that students are given the freedom to individualize their learning. Given the additional time for face-to-face interaction in the classroom, teachers can tailor activities that are relevant, hands on, student-centered, and experiential in nature.

\subsection{Benefits of a flipped classroom}

If educators are willing to move from the traditional model of teaching to a Blended Learning strategy, then research should consider the benefits and challenges of the Flipped classroom model as opposed to a lecture only approach. Morgan (2014) investigated the advantages and limitations of the flipped classroom. Four hundred fifty-three teachers tried the flipped classroom approach and indicated that most found it helpful, especially for students with special needs and those in advanced placement classes. Ninety-nine percent of these teachers said they would use the flipped classroom method again. Some schools, such as Clintondale High School in Michigan, had especially good results. The failure rate of ninth-grade mathematics students fell from forty-four percent to thirteen percent. The advantages cited by Morgan were: when the flipped classroom is implemented effectively, students are allowed to learn at an appropriate and differentiated pace, teachers have more opportunities to help individual students that find the content difficult to understand, a reduced cost of education as a consequence of providing instruction on a video platform so districts have fewer textbooks to purchase, and benefits the students that may not get much help with homework at home (Morgan, 2014).When students must miss class time, the flipped classroom provides a means for students to access school materials any time from multiple locations. Students can remain up-to-date per the curriculum calendar by viewing and reviewing the web-based instructional material. Although there seem to be many advantages presented by the author, the reduction of cost to do school business may not be one of those. Technological provisions require schools to produce, maintain, and access web-based instructional material, which can be expensive.

Educators who volunteered to participate in qualitative investigation felt positive about flipping instruction in a classroom. In the study by Bergmann and Waddell (2012), students tended to be more engaged in the flipped classroom environment. The study also noted the use of classroom time was more efficiently managed, and for the most part students were prepared prior to coming to class. The responsibility for learning was moved from the teacher to the student (Bergmann \& Waddell, 2012).Bergmann and Waddell intimated that in order for flipped learning to be successful, emphasis should be placed more on inquiry and project-based learning and less on standardized testing. This study was noteworthy in that both proponents and opponents of Flipped Learning were interviewed for this investigation.

\subsection{Problems with a flipped classroom}

As with any educational practice, there are bound to be disadvantages .The Flipped classroom model has drawbacks that need to be considered prior to implementation. Flipping the classroom allows for individualized differentiated instruction in the classroom, but does not always hit the mark for each student's learning style. Some students are not suited to learn from material presented in the form of an instructional video. Likewise, students may choose 
not view the video lessons (Bergmann \& Waddell, 2012).Struggling students may not benefit as much from the flipped model as would more advanced learners or those whom can learn from a variety of teaching and learning methods. Students have reported having difficulty staying motivated watching video lessons at home and often fast forward to get through the video lesson, thus missing important conceptual pieces. Students have been found to exhibit frustration when they could not get immediate responses to their questions during video instruction (Johnson, 2013). Some might say the biggest issue to flipping the classroom is accessibility to the technology needed to view web-based instructional materials. Not all students have access to the essential technologies necessary for viewing the lessons. Families with lower incomes may not have the means financially to access the Internet as required for flipped classroom lessons (Bergmann \& Waddell, 2012).As with any teaching strategy or innovation, educators must consider the possible shortfalls or limitations that may affect the outcome of a student's participation, learning, and achievement in a targeted subject area. Educators must not only be innovative with technology tools, but flexible to adjust to the individual needs of the student population.

\subsection{Conclusion}

The review of the literature focused on the impact of technology for learning and teaching mathematics and the Flipped classroom model. Each of these topics gives insight into the importance of technology in today's educational system and provides support to the flipped classroom as an educational model. The majority of the literature surveyed for the flipped classroom investigates how this model affects student academic achievement.

\section{Research Questions}

To obtain a better understanding of whether the use of web-based instructional videos via a Flipped classroom model in a high school mathematics class would affect the attitude, perceptions, or engagement of students, the following three research questions guided this research inquiry:

1. How does the flipped classroom model impact the attitudes, perceptions, and engagement of high school students in a mathematics classroom?

2. To what extent will a Flipped classroom model affect the motivation to learn mathematics for high school students?

In this study, the instructional videos were made available to students via the researcher's school website (see Figure 1) built using Google Sites. Students accessed the videos in the "Videos - Student" folder (see Figure 2). 


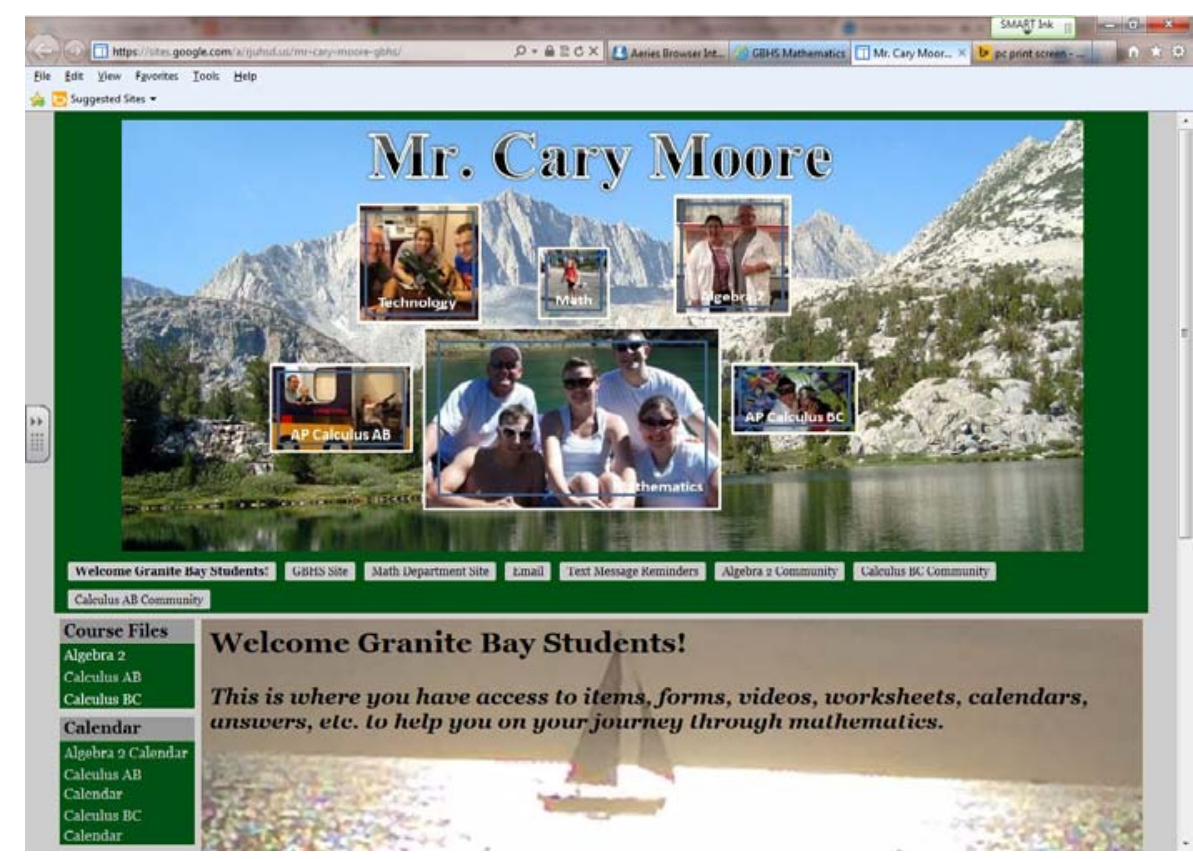

Figure 1. Teacher's Website

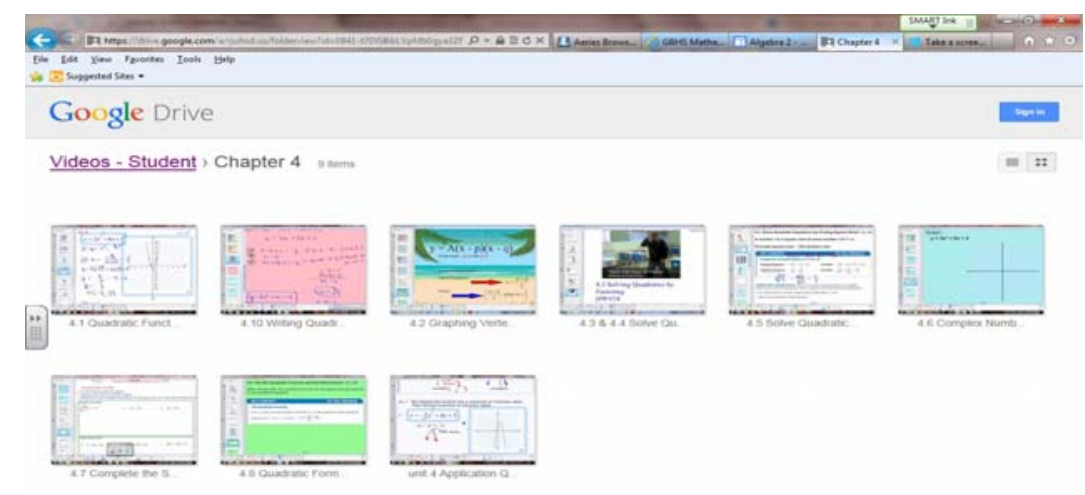

Figure 2. Folder for Instructional Videos

\section{Methods}

This action research study took place in a local high school Algebra 2 classroom located in Granite Bay, California. The high school is a public school located in a middle-to-upper class community. The class was held during second period in a four period block schedule format. The duration of the Algebra 2 class was August 2014 to December 2014. The school serves students in grade-levels nine through twelve.

\subsection{Participants}

Thirty-five students enrolled in the second period Algebra 2 class were invited to participate in this research study. All four class-levels were represented in the study: four were freshmen, 
ten were sophomores, eight were juniors, and three were seniors. No students enrolled in the Algebra 2 were designated with special learning needs. Five of the twenty-five participants volunteered to be interviewed after the treatment period. These interviews took place during the last week of the fall semester.

\subsection{Measures}

Several measures were used during this study to determine attitudes, perceptions, engagement, and motivation of mathematics students using instructional videos within a flipped classroom setting. Students were given survey questions and interviewed in order to elicit their opinions of elements of the flipped classroom model. The researchers also observed and noted student behaviors during the treatment period. From these data gathering tools, six categories of overall student feelings were coded: understanding/comprehension, perceptions, attitude, engagement, motivation, and retention.

\subsection{Data Collection and Methods of Analysis}

Quantitative and qualitative data has been collected for this action research study. A pre-treatment survey was administered to the participants to determine baseline demographics and a post treatment survey was administered to explore the use of technology (flipped classroom) for academic learning or assistance. Additionally, qualitative data was gathered from interviews administered to five randomly chosen participants. Qualitative data also included researcher's observation notes. This gave depth to the investigation and provided information to the extent to which the flipped classroom provided understanding or motivation to the students. The results were analyzed to determine correlations of demographics, perceptions, attitudes, and engagement of students' understanding, comprehension, and retention of mathematical concepts due to elements of the Flipped classroom model.

\section{Results}

This study investigated how the flipped classroom model may change attitudes, perceptions, and engagement of high school mathematics students in relation to their understanding, comprehension, and retention of mathematical concepts. In addition, this study investigated to what extent a flipped classroom model affects the motivation of high school students to learn mathematics. The research was an exploratory mixed-methods design. For the numerical data, statistical analysis was performed to compare the data to determine the significance of demographics, attitudes, perceptions, and engagement due to the technological elements of a flipped classroom. Qualitative data from teacher's observation notes, answers to the post treatment open-ended survey and interview questions were coded to identify patterns of common opinions from the students as indicators of motivation, attitudes, perceptions, or engagement to mathematics content relative to the flipped classroom.

\subsection{Demographic Data}

The initial five questions of the survey were used to collect demographic information from the participants. Question 1 (see Figure 3) asks, "What is your gender?"48\% (12) were female 


\section{Macrothink}

and 52\% (13) were male, thus gender was relatively evenly split. Question 2 (see Figure 4) surveyed participants' grade level. The question asked, "What is your grade level?" $16 \%$ (4) were freshmen, $40 \%$ (10) were sophomores, 32\% (8) were juniors, and $12 \%$ (3) were seniors. The majority of the participants in this study were sophomore and junior level Algebra 2 students. The demographic Question 3 concerned accessibility to technology needed to view instructional videos outside the traditional high-school classroom setting. The question asked, "What kinds of technologies are available at home?" $100 \%$ of the students had either Smartphones or tablet devices, giving students access to school materials wherever Internet connectivity was available. $100 \%$ of the students had either laptop or desktop computers at home, allowing study participants access to instructional videos.

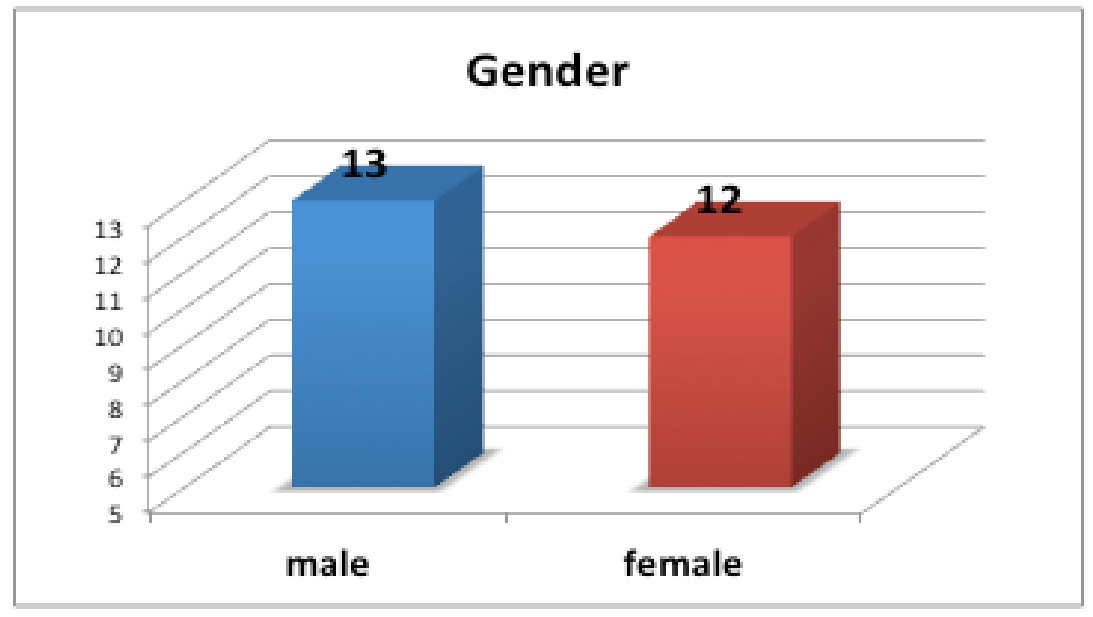

Figure 3. What is your Gender?

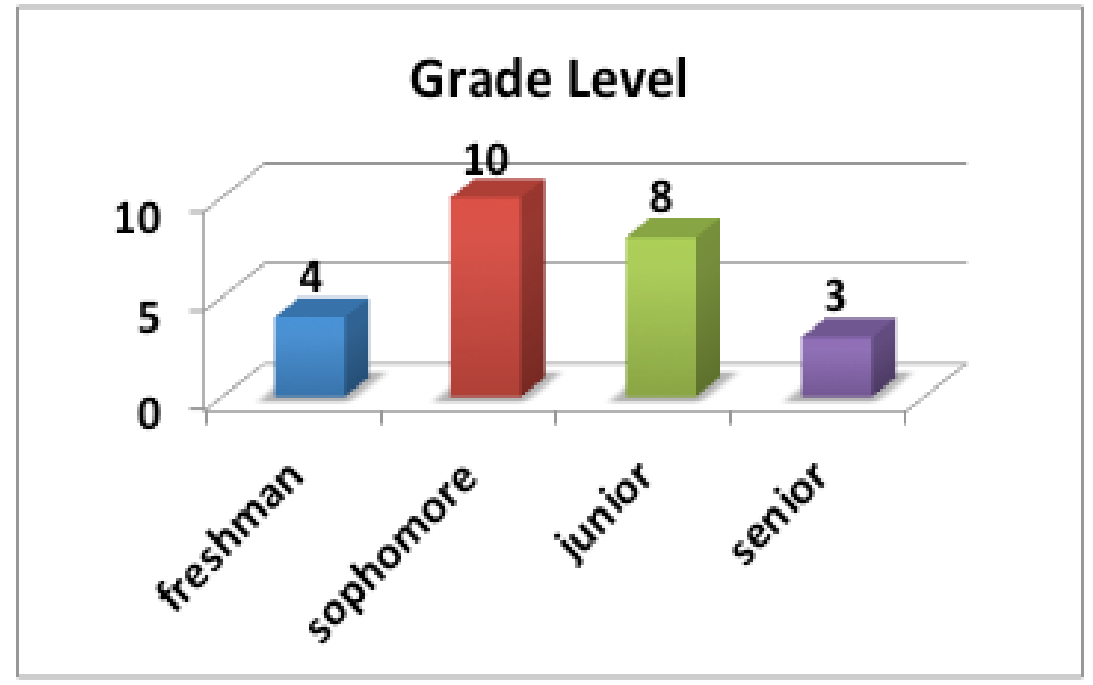

Figure 4. What is your grade level?

Question 4 concerned the use of technology by the guardians of the participating students. The question asked, "Do your parents use computers, tablets, or mobile technology?" $100 \%$ of the parents used computers, tablets, or mobile technology. Question 5 (see Figure 5), the last demographic inquiry, asked the question, "How often do you use 


\section{Macrothink

technology outside the classroom?" $92 \%$ (23) of the students use technology more than three times per week outside of the classroom and 8\% (2) of the students use technology three times per week outside of the classroom. Question 6 (see Figure 6), asked the question, "How often do you use the Algebra 2 instructional videos outside the classroom?" $28 \%$ (7) never viewed the instructional videos, $52 \%$ (13) viewed the videos once per week, $12 \%$ (3) viewed the videos twice per week, and $8 \%$ viewed the instructional videos three times per week.

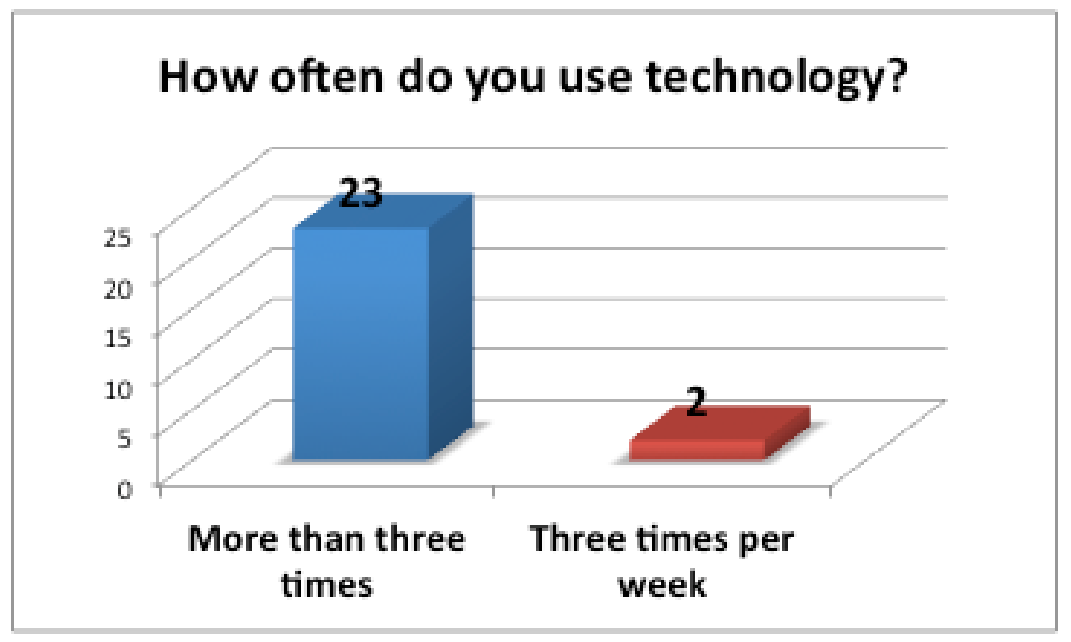

Figure 5. How often do you use technology?

\subsection{Quantitative Results: Post Survey}

Students were given a post survey in order to elicit their opinions of elements of the flipped classroom model. The quantitative results that address students' attitude, perceptions and motivation will be presented below.

\subsubsection{Attitudes and Perceptions}

The following quantitative results address the attitudes and perceptions of students' understanding of mathematics in the flipped classroom environment. Question 7(see Figure 7) from the survey asks, "Did you like using the web-based instructional videos?" $56 \%$ (14) of the students liked using the instructional videos to get help with Algebra 2 concepts and 44\% (11) did not like the videos. Students liked web-based instructional videos slightly more than disliking them. Question 8 (see Figure 8), "Did you find the instructional videos useful to help you better understand the Algebra 2 content?" $64 \%$ (16) responded that the videos were useful and 36\% (9) of the Algebra 2 students did not feel the instructional videos were useful to better understand Algebra 2 concepts. According to the survey, $77 \%$ of male students (see Figure 9) found that the instructional videos helped to better understand mathematical content. Thispercentage was significantly higher than the female perception of the usefulness of the instructional videos in an Algebra 2 class. 


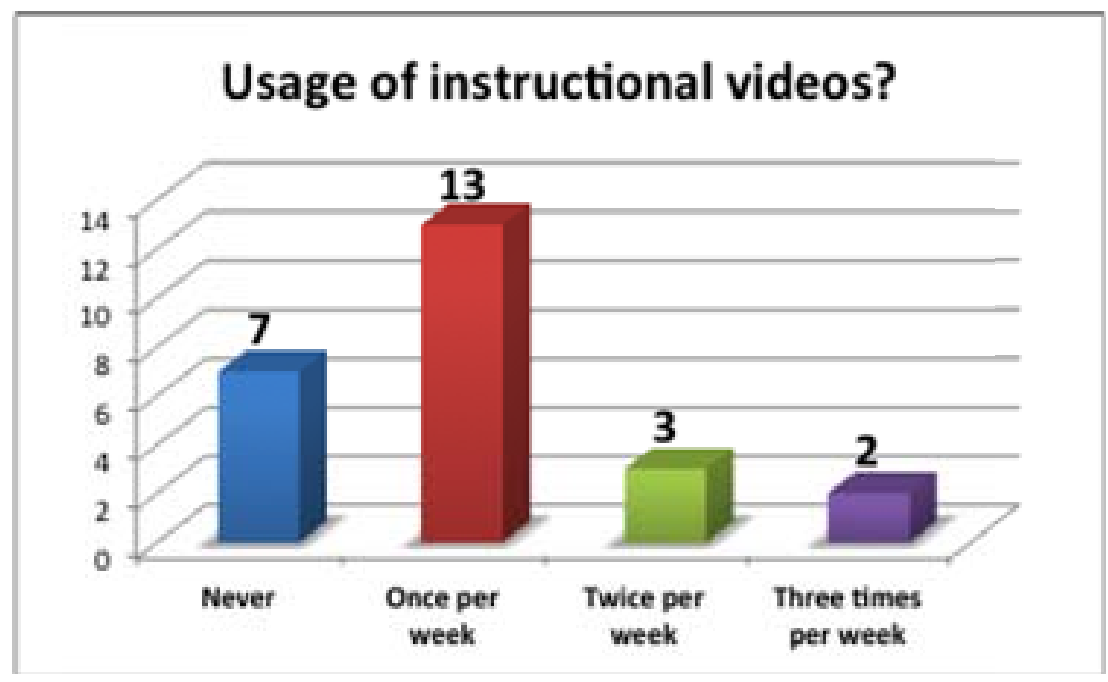

Figure 6. How often did vou use Algebra 2 instructional videos?

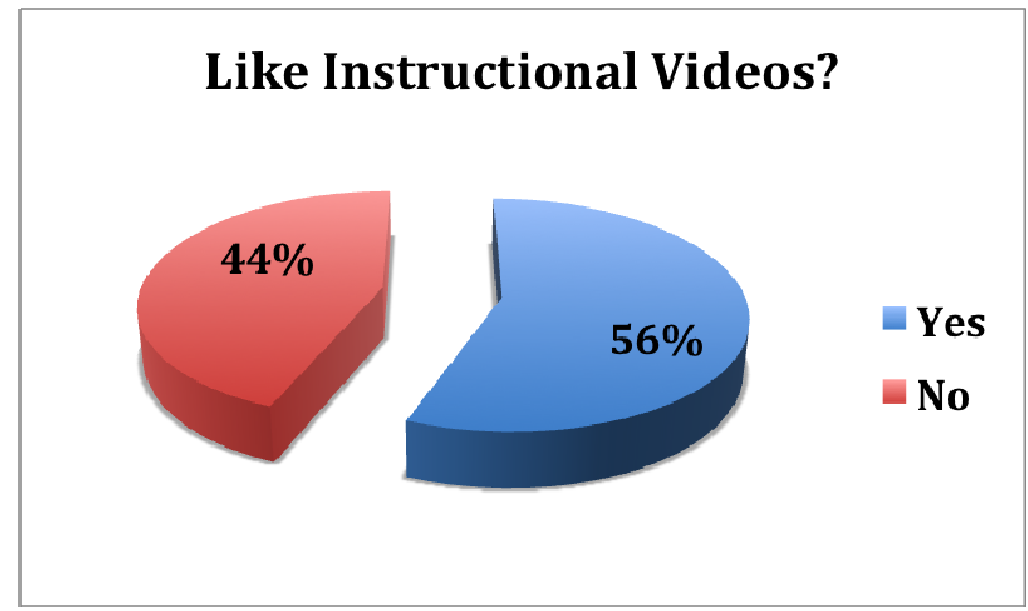

Figure 7. Did you like using the instructional videos?

The percentage of older students finding the videos useful was greater than the younger students. $100 \%$ (3) of the senior students found the videos useful to understanding mathematics.Question 11 (see Figure 10), "Did the use of instructional videos make learning more enjoyable?" $68 \%$ (17) did not feel that using instructional videos helped make learning mathematics more enjoyable and $32 \%$ (8) students thought that the use of videos did make learning more enjoyable. When looking at the data from the female gender perspective, (see Figure 11) 83\% (10) female students did not find that using instructional videos made Algebra 2 more enjoyable. This percentage was much higher than the male participants in this study. Only $17 \%$ (2) found the experience of watching videos made mathematics more enjoyable. 


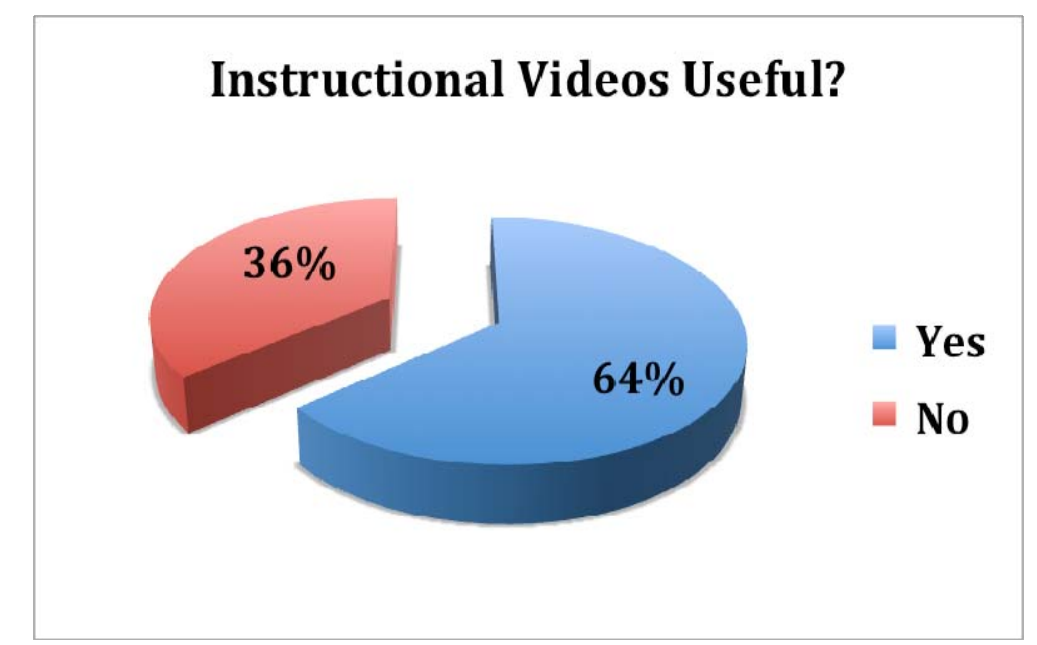

Figure 8. Do you think there is value in using instructional videos in an Algebra 2 class?

\subsubsection{Motivation}

The following survey results address the motivation level of students' to learn mathematics in the flipped classroom environment. Question 9 (see Figure 12), "Did the instructional videos help you learn at your own pace?" $32 \%$ (8) of the students did not find the instructional videos helpful in learning at their own pace and $68 \%(17)$ of the students felt that the videos did help them to pace their learning to fit their needs. The majority of the students found that the instructional videos helped them control their own pace of learning mathematics. Question 12 (see Figure 13), “How often did you take notes on the content on the instructional videos?" $56 \%$ (14) students never took notes of the content from the instructional videos, 32\% (8) students took notes once per week, and 12\% (3) students took notes more than once per week. The majority of the students rarely took notes from the videos. Question 13 (see Figure 14);"Do you think there is value in using instructional videos in an Algebra 2 course?" $92 \%$ (23) students felt there is value in using instructional videos in a mathematics course and $8 \%$ (2) students did not think that videos were a valuable tool for Algebra 2 instruction. The majority of the students felt that web-based videos for instructional purposes are valuable in a mathematics classroom. 


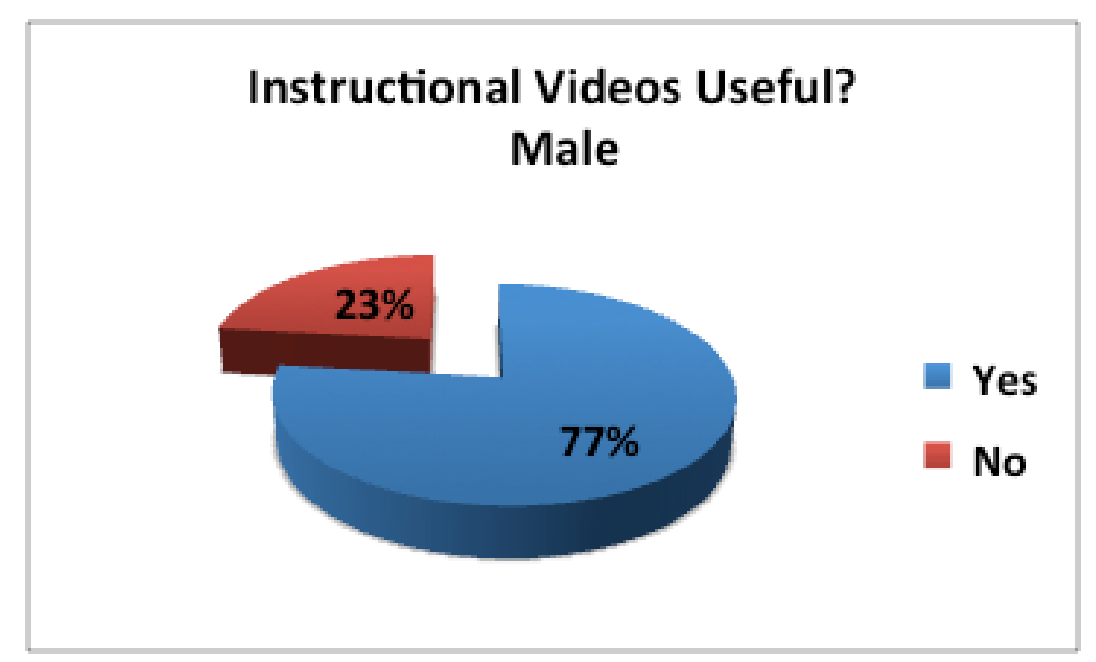

Figure 9. Do you think there is value in using instructional videos in an Algebra 2 class?

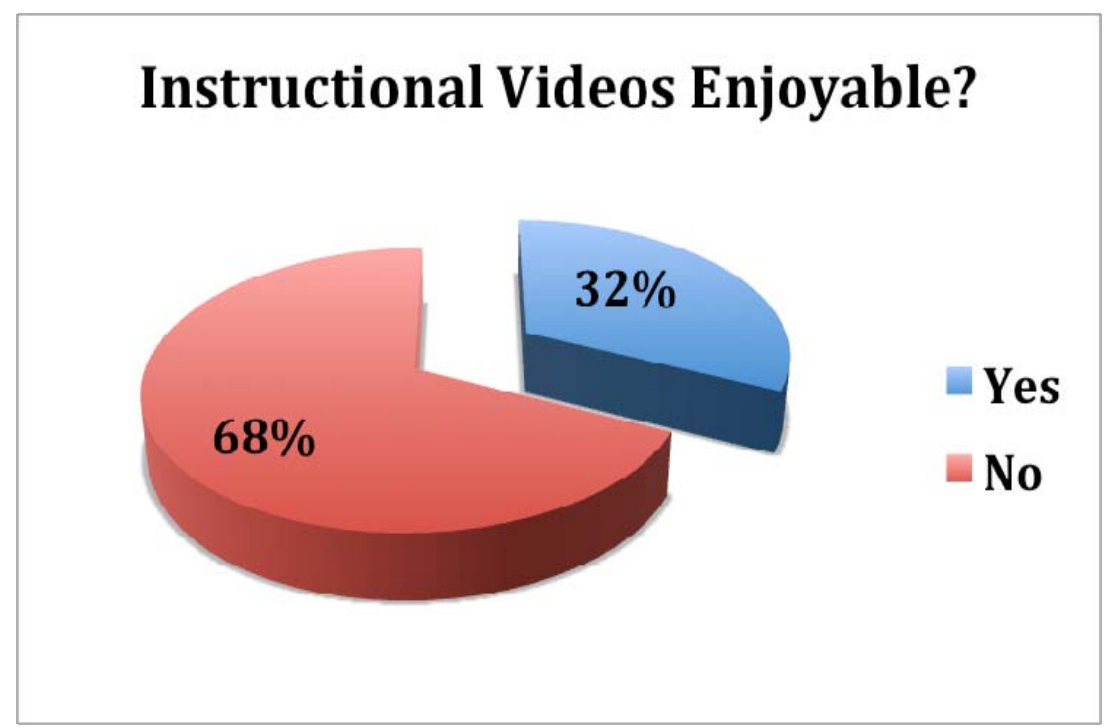

Figure 10. Did the use of instructional videos make learning Algebra 2 more enjoyable? 


\section{Instructional Videos Enjoyable? Female}

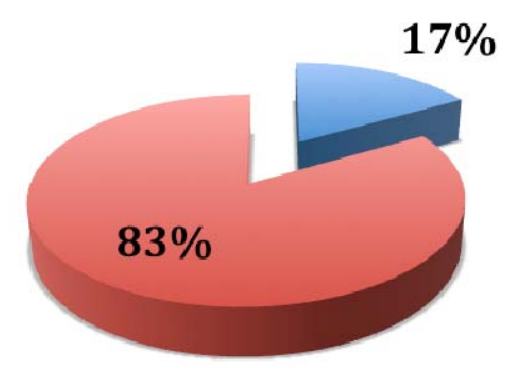

Yes

No

Figure 11. Did the use of instructional videos make learning Algebra 2 more enjoyable?

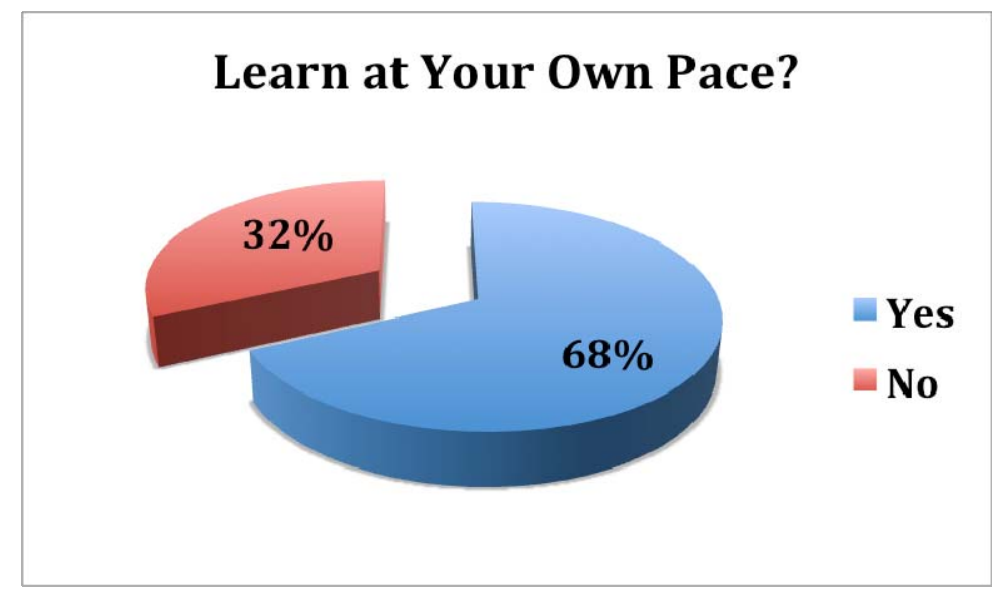

Figure 12. Did the instructional videos help you learn at your own pace?

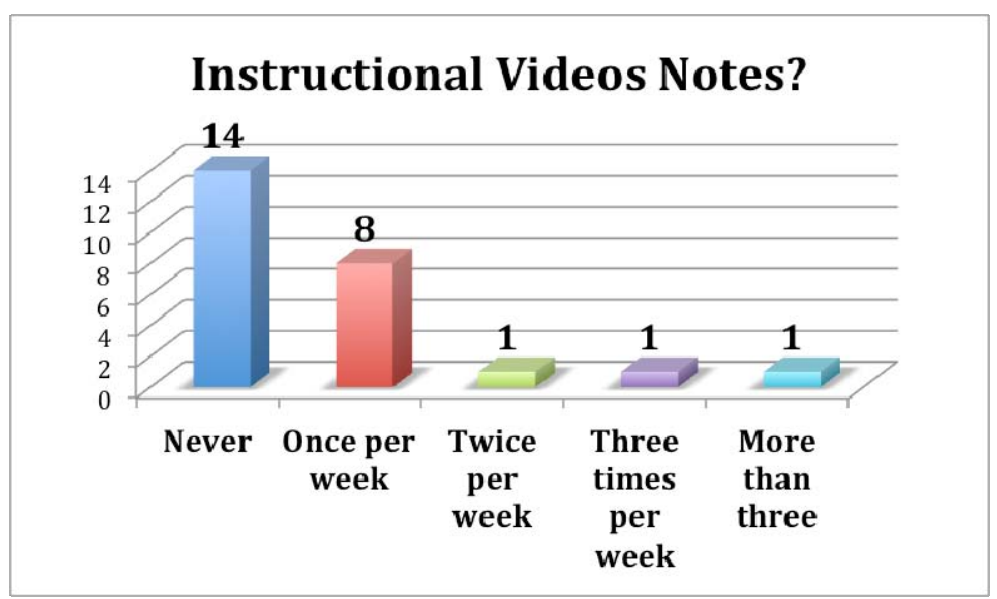

Figure 13. How often did you take notes from the instructional videos? 




Figure 14. Do you think there is value in using instructional videos in an Algebra 2 class?

\subsection{Qualitative Results: Post Survey}

Students were given the post survey questions in order to elicit their opinions of elements of the flipped classroom model. The qualitative results that address students' attitude, perceptions, engagement and motivation will be presented below.

\subsubsection{Attitudes and Perceptions}

There were several open-ended qualitative response questions in the post-treatment survey. These questions were used to assess student attitudes, perceptions, engagement and motivation toward understanding mathematics in a flipped classroom environment. They were also used to determine the extent that a flipped classroom model affects the motivation of students to learn mathematics. Common themes (attitudes, perceptions, engagement and motivation) within student responses were recorded, and subsequently coded. Question 7 asked students to "explain what they liked about the instructional videos used in the flipped classroom model." Twenty-four of the twenty-five students(96\%) surveyed responded to this question. Students mentioned that the instructional videos helped them to learn at their own pace. One student stated, "I can learn the lesson at my own pace."In the same vein, some students felt the videos helped them to stay on task and on the classroom schedule. The students liked staying on pace with the class schedule. One student stated, "It is like the teacher is there with me."

Questions 9 asked students to "explain how the instructional videos helped them to learn at their own pace."Nineteen out of the twenty-five students (76\%) answered the question. Most of the respondents mentioned the controls of their viewing devices (pause, rewind, and fast-forward) allowed them to watch the videos at a pace that was comfortable for them. One student reported, "I was able to pause to copy down important information before moving forward with the video."Another noted, "I could rewind and watch things I missed. I could also fast-forward or skip things I didn't need."Question 11 asked students to "explain if the use of instructional videos made learning mathematics more enjoyable."Fourteen out of 
the twenty-five students (56\%) responded to this question. There was not a common theme to this question. The variety of answers encompassed students having better focus at home and having more control over the pace of the learning process. One student mentioned, "My generation is tech savvy and prefers access to learning through web-based resources."Question 13 asks the students to "explain if they think there is value in using instructional videos in an Algebra 2 course." Twenty-two of the twenty-five students (88\%) answered this last open-ended question. A student said, "The videos guide you through a problem at a pace that can be controlled."

\subsubsection{Engagement}

The following qualitative results from the open-ended survey questions address the engagement of students' understanding of mathematics in the flipped classroom environment. Question 7 asked students to "explain what they liked about the instructional videos used in the flipped classroom model."Twenty-four of the twenty-five students(96\%) surveyed responded to this question. Four students stated that the videos helped them to connect mathematical concepts with the assigned tasks. One student said, "The videos helped me to understand the lessons and activities."Question 8 asked students to "explain if they found the instructional videos useful to help better understand the Algebra 2 content?"A few reported the web-based resources helped to deepen their understanding of mathematical concepts, which connected to assigned activities. Questions 9 asked students to "explain how the instructional videos helped them to learn at their own pace." A theme that developed from this question is: the web-based videos gave students' added support and resources to connect with mathematical concepts. One participant said, "The videos gave me additional references to help with things I didn't understand."Another stated, "The videos helped me to remember concepts from math class or when I was confused I could watch the videos for additional help."Question 13 asks the students to "explain if they think there is value in using instructional videos in an Algebra 2 course." A common theme for this question is: instructional videos provide an additional web-based resource to help students connect with the expected learning goals. One student noted, "The videos can provide extra help if a student doesn't understand a problem or the lesson."

\subsubsection{Motivation}

The following qualitative results from the open-ended survey questions address the extent that a flipped classroom model affects the motivation for students to learn mathematics. Question 7 asked students to "explain what they liked about the instructional videos used in the flipped classroom model."Six students liked having the instructional videos available for when they missed class for a variety of reasons (illness, sports, extra-curricular events), and to learn the lesson on their own in order to stay up with their classmates. Question 8 asked students to "explain if they found the instructional videos useful to help better understand the Algebra 2 content?"Five of the students mentioned that the instructional videos were good for reviewing mathematical concepts to understand and complete homework or to prepare for upcoming assessments. It may be worth mentioning that homework, projects, and summative assessments have point values that contribute to student 
grades. Several students noted that the web-based videos were useful for when students miss class. They could view the videos at home to prepare for the next school day activities in their Algebra 2 class. Question 13 asks the students to "explain if they think there is value in using instructional videos in an Algebra 2 course." A common theme for this question was: students can stay on track with the Algebra 2 class when class is missed for whatever reason, they can control their own pace of learning mathematics concepts. One student noted, "If someone misses a day of school, there is something to look at to learn the lessons."

\subsection{Qualitative Results: Interviews}

The researchers conducted five interviews with five students at the end of the flipped classroom treatment period. The interview questions were used to gain insight into student attitudes, perceptions, and engagement toward understanding mathematics in a flipped classroom environment. The interviews were also used to determine the extent that flipped classroom model affects the motivation to learn mathematics. Common themes in the student interview responses were recorded and coded. These themes included attitudes, perceptions, engagement and motivation. Each theme will delineated below.

\subsubsection{Attitudes and Perceptions}

The following qualitative results from the participants' responses to interview questions address the attitudes and perceptions of students' understanding of mathematics in the flipped classroom environment. When asked, "Explain how you viewed the instructional videos and the ways in which you made notes from the videos? The respondents stated they typically watched videos at home. All participants mentioned watching the videos at a pace dictated by the need for understanding the material at a pace comfortable to them. Student B mentioned, "I could work problems at a pace in which I can learn better."Student C stated, "I would write down things, ideas, formulas, and problems that I felt would be helpful. I could learn at my own pace."The next interview item was for the students to "tell their opinion as to what are the positive aspects of the flipped classroom experience."The students felt that having the instructional videos available anytime and anywhere was advantageous in that anything you needed as far as instruction could be accessed at their convenience. They felt the videos could be watched at a location and time frame of their choice. Several students stated that controlling the pace of learning was a positive aspect of the flipped classroom. Student A mentioned, "I could pace myself watching the videos by using the pause and rewind buttons. I could learn the lesson in steps and chunks."When asked, "Explain how you viewed the instructional videos and the ways in which you made notes from the videos", the respondents would watch the instructional videos in conjunction with doing activities related to the content of the video. Student B mentioned, "I was able to engage with the instruction better at home with less distractions." Student A said, "I found watching the instructional videos more helpful than reading the textbook."Student D noted, "I watched the videos as an extra resource, especially before a test."She added, "I could pause, rewind, or fast-forward to see the work done step-by-step, rather than seeing examples in the book that are already completed.I liked to hear the teacher's thought process while instructing on the videos." 


\subsubsection{Engagement}

The next interview item was for the students to "tell their opinion as to what are the positive aspects of the flipped classroom experience."The students felt being able to watch the math instruction with little or no distractions was helpful. When absent from class, they felt that there was a web-based resource for them to connect with to keep up with the content presented that day. Student E mentioned, "I could watch the videos at home with no distractions."This interview item asked the students to "describe their ideas and feelings on the value of using instructional videos in a mathematics class." The number one theme provided by the students was that instructional videos are important to academic instruction, learning and comprehension, especially in mathematics. Student C noted, "Instructional videos are especially important in math, where it is necessary for students to develop a deeper understanding of math."Student D continued this thought with, "Math concepts don't always sink in at first glance. Math is a subject that requires multiple looks at examples for some students. The videos are important in a math class."Student B expressed, "The videos are important to help me review and gain a better understanding of the math learning goals, as opposed to memorizing math facts that will soon be forgotten."

\subsubsection{Motivation}

The following qualitative results from the interview questions address to what extent a flipped classroom model affects the motivation for students to learn mathematics. When asked, "Explain how you viewed the instructional videos and the ways in which you made notes from the videos", the respondents would use the features from their computer to pause, rewind, fast-forward, or skip topics on the instructional video. The next interview item was for the students to "tell their opinion as to what are the positive aspects of the flipped classroom experience."Some students mentioned the videos tended to help them to not to fall behind in the class when absent for whatever reason. The interview then asked the students to "describe their ideas and feelings on the value of using instructional videos in a mathematics class."One theme from this inquiry was that the students saw the importance of having a resource that can be used anytime and anyplace with a computer that has access to the Internet. Student A mentioned that, "The videos are good to have available when students miss class."Student D stated, "If I or other students missed days of school, then the videos provide a great resource that students can use to learn the lesson and to stay on pace with the rest of their classmates."Another thematic topic provided by a couple of students was that the instructional videos are an additional resource to help students achieve positive academic results. Student B noted, "The videos helped me to prepare for tests, so that I can get a good grade. They help me prepare for the next steps in high school math."

\subsection{Qualitative Results: Class Observation Notes}

The researchers made observations during the course of the flipped classroom treatment period and noted several instances of student engagement in the classroom environment. After viewing the instructional videos at home, students were making connections between the content on the videos and the enrichment activities related to the unit learning goals. Group discussions during problem solving activities were filled with informed dialogue. 
Students were using mathematics-appropriate vocabulary found on the web-based lessons as opposed to non-specific references such as "this, that, or it". The participants often referred to the video content when supporting their own conclusions as to a result in their class work. Those who missed class for a variety of reasons (illness, family vacation, sporting events, academic competitions, robotics, dance, yearbook obligations, student government activities, etc.) tended to take responsibility in watching the instructional videos in order to keep pace with the rest of the class. Students had more time during class to participate in hands-on learning activities that lent themselves to an added level of engagement for the learners with the expected outcomes. The researchers noted many students were ahead of schedule in completing required elements of the Algebra 2 course. The common thread for students was, "After watching the videos, I was able to complete my homework ahead of time."The researchers observed there was less need for direct instruction to the entire class. There were significantly fewer students that required additional help. The instructor noted students were taking more responsibility for their learning as well as connecting the mathematical concepts to what they produced in class in order to assess their knowledge.

\section{Discussion}

The topics of: attitudes, perceptions, engagement, and motivation of students in a flipped classroom environment will be discussed to answer the two guiding research questions, "How does the flipped classroom model impact the attitudes, perceptions, and engagement of high school students in a mathematics classroom?"Also, "To what extent will a flipped classroom model affect the motivation to learn mathematics for high school students?"

\subsection{Attitudes and Perceptions}

The purpose of this action research project was to answer two questions. First, "How does the flipped classroom model impact the attitude, perceptions, and engagement of high school students in a mathematics classroom?"There are two parts to this question to be discussed separately. Initially the researchers will address the attitudes and perceptions of the students in a flipped classroom, and then undertake the topic of student engagement in that environment. The results suggest the flipped classroom model has a positive impact on the attitudes and perceptions of students in a mathematics school environment. Fifty-six percent of the participants surveyed liked flipping the classroom in that they could watch instructional videos at home (see Figure 7). This helped them to stay on task or even get ahead of the expected pace of the Algebra 2 course. As noted by one of the participants, students are less worried about falling behind in class because of the access to web-based instruction at home. Sixty-four percent of the students surveyed found that instructional videos used in the flipped classroom helped them to better understand concepts in Algebra 2 (see Figure 8).Having the lessons available at home, allowed students' additional time in class to discuss and practice the unit objectives. Student A said, "I could learn the lesson in steps and chunks."The students felt the instructional videos were useful, because the lessons were available anytime anywhere. The videos could be viewed at a location and time of their choice. One student mentioned, "It's like the teacher is right there with me as I watch the lesson at home."Student C noted, "Instructional videos are especially important in math, 
where it is necessary for students to develop deeper understanding of mathematics."Although the students liked having the lessons available at home and understood the usefulness of this part of the flipped classroom model, they did not feel viewing web-based videos made the experience of learning mathematics more enjoyable. Sixty-eight percent of the students surveyed did not find that using instructional videos in a flipped classroom made learning mathematics more enjoyable (see Figure 10).Eighty-three percent of the female participants did not enjoy viewing web-based instruction (see Figure 11).One student stated, "I prefer in-class lessons."Another said, "It's just like learning at school, but I'm at home."A third countered, "Students are more technologically savvy and prefer to learn through other web-based sources, not just listening to the teacher in class."

The flipped classroom model has a positive impact on the attitudes and perceptions of students in a mathematics course in that they see the need to have more resources and time to understand the material presented in a mathematics class, and like to have access to web-based videos for added support. They find these resources especially important in mathematics. Students may have been less inclined to enjoy the videos because they contained only essential information. The content of the instructional videos included development of concepts, definitions, properties, examples, common mistakes, and simple application problems to consider. In essence, the videos provided facts and examples for foundational knowledge so students had the basic tools and skills to participate in extended learning activities. The instructor tried the produce web-based videos that were fifteen or less minutes to view. This left little room to add content to the videos that might have provided additional elements such as humor or video production visuals in order to make them more enjoyable to watch. The researchers would suggest keeping the videos less than ten minutes in length and insert content that provides added interest to the information being conveyed to the students.

\subsection{Engagement}

The second aspect of the first question addresses the engagement of students in the flipped classroom model. From the responses to the open-ended survey and interview questions, as well as observations from the researchers, students seemed to be more engaged with the problem-solving tasks and activities in the classroom after learning lessons via instructional videos outside the confines of school facilities. Ninety-two percent of the students felt there was value in using web-based instructional videos in a mathematics course as part of a flipped classroom (see Figure 14).Four students noted the instructional videos used in a flipped classroom helped them to connect mathematical concepts with the assigned tasks within a unit. One student mentioned, "The videos helped me to understand the lessons."Student B stated, "I was able to engage with the instruction better at home with less distractions."The researchers observed the students making connections between the content of the videos and the unit objectives practiced in class. One example noted by the researchers was the observation of students in a discussion group taking the basic concepts of exponential growth provided on the web-based instructional video, and applying this knowledge to developing personal financial investment growth models. The researchers noted that students who watched instructional videos at home were able to complete assigned tasks 
independently, often prior to the due date. Additionally, students had more time in class in which to participate and engage with their peers in rich mathematical discussions and with relevant hands-on activities. The flipped classroom model had a positive impact on students engaging with the content in a mathematics class. Providing web-based instruction outside of class allowed students to learn content in an atmosphere comfortable to their learning style where the pressure of time, space, and attention were less of a factor. Students were then able to participate in student-centered problem-solving activities equipped with knowledge to engage with their peers and with the task at hand. The researchers' findings in this study were similar to those described by Bergmann and Waddell in their research. They noted the use of classroom time in a flipped setting was more efficiently managed, and for the most part students were prepared prior to coming to class. Students tended to be more engaged in the flipped classroom environment. The responsibility for learning was moved from the teacher to the student (Bergmann \& Waddell, 2012).

\subsection{Motivation}

The second question addressed by this action research project was, "To what extent will a flipped classroom model affect the motivation to learn mathematics for high school students?'The results suggest the flipped classroom provides students with flexibility and ownership in the learning process, which in turn motivates students to learn content in a mathematics course. Sixty-eight percent of the students stated the flipped classroom instructional videos helped them learn at their own pace (see Figure 12).Sixty-eight percent of the participants responded they used the control features on their computer to watch the instructional videos. Nine students noted in their open-ended responses that they controlled their learning style and pace of learning in the flipped classroom. They used the functions of their viewing device (computer, tablet, or Smartphone) to pause or rewind the videos when needed. Some students mentioned using the fast-forward feature to move past information they already understood. Student B said, "I could work problems at a pace in which I learn better."Others noted they now had the resources to access lessons in order to prepare for classroom activities, work examples, and review for tests. Ninety-two percent of the students felt there was value in using web-based instructional videos in a mathematics course as part of a flipped classroom (see Figure 14). The students had a resource outside the classroom, which directly impacted their learning of mathematics. Student B stated, "The videos helped me to prepare for tests, so that I could get a good grade.'The resources provided in the flipped classroom also helped the students remain on pace with the course objectives. If students missed class for any one of a variety of reasons, they were able to access the lessons online to make up for missed time. Students D noticed, "If someone misses a day of school, there is something to look at to learn the lessons."Morgan noted in his research, when the flipped classroom is properly implemented, students are allowed to learn at an appropriate and differentiated pace, teachers have more opportunities to help individual students that find the content difficult to understand, and it benefits the students that get little help with homework at home. When students must miss class time, the flipped classroom provides a means for students to access school material any time from multiple locations (Morgan, 2014).Students overwhelmingly agreed the instructional videos provided in the flipped 
classroom model were valuable tools for a mathematics curriculum. Since Algebra 2 relies heavily on scaffolding ideas and concepts to understand and complete real world math problems, missing any one topic in the course of a mathematics class can create problems for students to succeed. Having videos available for students to view is important. Student C noted, "I would write down things, ideas, formulas, and problems that I felt would be helpful. The student continued, "Instructional videos provide an extra needed resource for math."Another mentioned, "Lessons on videos are especially needed in math."The flipped classroom model has a positive effect on motivating students to learn mathematics. As suggested by the participants, flipping the classroom allows students to be responsible for their learning outcomes and experiences. The students control the time and location of their learning environment. Students understand the value of having additional technology based resources outside the classroom to help them gain a working knowledge of the objectives in a mathematics course. These are all factors provided in a flipped classroom model that help motivate students to participate in the process to learn and use mathematics in real world application problems.

\section{Conclusion}

There were several findings in this action research project that contribute to the study of the flipped classroom model. The first is, students like the availability of web-based resources to help in their learning of mathematics. The students did not necessarily enjoy the aspect of learning mathematics from a video at home, but they understood the importance of instruction outside the classroom to provide a supportive and relative learning experience within the classroom. Second, students liked the idea of being responsible for their learning by having a place and time of their choosing outside the confines of the classroom to explore and learn concepts in mathematics relevant to expected course objectives. They liked having features available on their viewing device to control the pace of learning. Third, the students understood the benefit of having a web-based resource, like instructional videos from the flipped classroom, to help develop knowledge and understanding in a difficult, but necessary, subject of mathematics.

This study had a limited number of participants due to the availability of classes lending themselves to being flipped. A larger sample size of participants, with broader cultural and socio-economic diversity, would have enriched and been more beneficial to this study. The researchers felt using different and more concise research questions would have clarified some of the discussion findings. This study investigated the attitudes, perceptions, motivation, and engagement of students in a mathematics flipped classroom. Research in other non-math subjects using the flipped classroom model would also be beneficial. Further research that explores the use of interactive web-based instruction in place of static instructional videos in a flipped classroom setting would be helpful. Research to examine the perceptions of students exposed to a variety of instructional video productions that may include humor, historical connections, be strictly factual, variance in duration, or variation in the number of concepts covered in one video would help further the study of the flipped classroom model. 


\section{Macrothink}

The flipped classroom is a strategy that can create more time and space in the traditional classroom for student-centered meaningful learning activities. Teachers need to design their classroom activities moving away from the old methods of knowledge gained through lecture (sage on the stage) and practice through uninteresting textbook problems. This study affirmed students appreciate a diverse approach to teaching, learning, and showing what they know. With the advances of new educational technologies and social media, the options to provide a rich learning experience for today's students maybe limitless. The flipped classroom model is one-method teachers should consider as a vehicle to expose students to relevant technological learning resources.

\section{References}

Bergmann, J. \&Sams, A. (2012).Flip your classroom: Reach every student in every class every day. International Society for Technology in Education.

Bergmann. J. \& Waddell, D. (2012). To flip or not to flip. Learning \& Leading with Technology, 39(8), $6 . \quad$ Retrieved from http://www.iste.org/Content/Navigation/Menu/Publications/ LL/L_L.htm

Herreid, C. F., \& Schiller, N. A. (2013).Case studies and the flipped classroom. Journal of College Science Teaching, 42(5), 62-66.

Johnson, G. B. (2013). Student perceptions of the flipped classroom.

Morgan, H. (2014). Focus on technology: Flip your classroom to increase academic $\begin{array}{llll}\text { achievement. } & \text { Childhood 239-241. }\end{array}$ http://dx.doi.org/10.1080/00094056.2014.912076

Roseville Joint Union High School District.(n.d.). Retrieved November 21, 2014, from http://www.rjuhsd.k12.ca.us/

Strayer, J. F. (2007).The effects of the classroom flip on the learning environment: A comparison of learning activity in a traditional classroom and a flip classroom that used an intelligent tutoring system (Doctoral dissertation, The Ohio State University).

Strayer, J. F. (2012). How learning in an inverted classroom influences cooperation, innovation and task orientation. Learning Environments Research, 15(2), 171-193. http://dx.doi.org/10.1007/s10984-012-9108-4

Yapici, I. U., \& Akbayin, H. (2012).High school students' views on blended learning. Turkish Online Journal of Distance Education, 13(4), 125-139. 